\title{
¿Tiene género la escritura?
}

\section{Does writing have a gender?}

\section{Resumen}

El año 1993, la crítica cultural Nelly Richard publica un polémico artículo titulado “ ¿Tiene sexo la escritura?". A partir de este texto, pretendo, en primer lugar, discutir la interrogante que da título al artículo, afirmando lo siguiente: no, no tiene sexo la escritura; tiene género. En segundo lugar, me interesa abordar el planteamiento no separatista de Richard. Este se refiere a la consideración de la escritura femenina en tanto contrahegemónica, hecho que compartiría con escrituras de varones. Para Richard, ser varón no es determinante en la valoración de la escritura, por lo mismo, señala que el feminismo corre el riesgo de convertirse en gueto si no incluye escrituras de varones contrahegemónicos. Desde mi visión, si bien es cierto que existen diferentes escrituras contrahegemónicas, no es posible des-generizar la escritura ni menos incluir en un mismo territorio la escritura de mujeres y de varones, ya sean heterosexuales u homosexuales ni menos, catalogar sus producciones en el rótulo "escritura femenina".

Palabras claves

Nelly Richards; escritura de mujeres; narrativa femenina; sexo; género.

\begin{abstract}
In 1993, cultural critic Nelly Richards published a polemic article called "Does Writing Have a Sex?". From this text I aim, on the one hand, to discuss the question that gives her article a name by stating that no, writing does not have a sex; it has a gender. On the other hand, I am interested in addressing Richards' non-separatist perspective, which refers to the consideration of female writing as counter-hegemonic, a fact shared with male writings. For Richards, being male is not decisive in the appraisal of writing. Moreover, she points out that feminism is at risk of becoming a ghetto if it does not include writing from counter-hegemonic males. From my vision, while it is true that there are different counter-hegemonic writings, it is not possible to de-gender writing; much less to put female and male writings in the same
\end{abstract}


territory, whether they are heterosexual or homosexual, and even less, to catalogue their productions under "female writing".

Keywords

Nelly Richard; Women's Writing; Female Narrative; Sex; Gender.

El año 1993, la crítica cultural Nelly Richards publica el libro Masculino /Femenino: prácticas de la diferencia y cultura democrática en el cual destaca su polémico artículo “¿Tiene sexo la escritura?”. ${ }^{1}$ A veintiocho años de la aparición de este importante texto, elaborado por una de las más relevantes intelectuales chilenas, pretendo instaurar un diálogo que, en primer lugar, me permita responder a la interrogante que da título al artículo, afirmando lo siguiente: no, no tiene sexo la escritura: no, tiene género. En segundo lugar, me interesa abordar el planteamiento no separatista de Richard. Este se refiere a la consideración de la escritura femenina en tanto contrahegemónica, hecho que compartiría con escrituras de varones. Para Richard, ser mujer o varón no es determinante en la valoración de la escritura, aun así, señala que el feminismo corre el riesgo de convertirse en gueto si no incluye escrituras de varones contrahegemónicos, que compartirían un lugar y una estética marginal con las mujeres y otras minorías. Desde mi visión, si bien es cierto que existen diferentes escrituras contrahegemónicas, no es posible des-generizar la escritura ni menos incluir en un mismo territorio la escritura de mujeres y de varones, ya sean heterosexuales $\mathrm{u}$ homosexuales ni menos, catalogar sus producciones en el rótulo "escritura femenina". Me propongo, tal como dice Nagore García:

${ }^{1}$ En Masculino /Femenino: prácticas de la diferencia y cultura democrática. Santiago de Chile: 1993, Francisco Zegers Editor. 
[...] repensar la escritura femenina no como algo esencial a las mujeres/cuerpos sexuados en femenino, sino como un proceso subversivo de creatividad que sin duda va ligado a un posicionamiento político. Ya que no podemos olvidar, que aunque la categoría de género sea construida culturalmente, ésta tiene efectos materiales sobre las personas y sus cuerpos. (3)

La dimensión política está ligada, por tanto, al lugar de una autora ya sea biográfico o al interior del texto literario, un lugar desigual respecto al que ocupan las masculinidades social y simbólicamente. La política de género de la mujer reclama ante la exclusión, la necesidad de aparecer, por tanto, "La disputa por el derecho a aparecer -negado a ciertos sujetos- está en el corazón mismo del ejercicio de la política y es aquello que la moviliza, transforma y produce sociedades con configuraciones específicas" (Judith Butler en Castillo 285).

De acuerdo a María Lugones: "El dimorfismo biológico, la dicotomía hombre/mujer, el heterosexualismo, y el patriarcado están inscriptos con mayúsculas, y hegemónicamente en el significado mismo del género" (78). Esto significa que el binarismo hombre-mujer es considerado como parte esencial del género y que todas y todos somos asignados a uno de estos dos géneros (82). Así, sexo, tal como señala Anne Fausto-Sterling: "se refiere a los atributos físicos, y viene determinado por la anatomía y la fisiología, mientras que el género es una transformación psicológica del yo, la convicción interna de que uno es macho o hembra (identidad de género) y las expresiones conductuales de dicha convicción" (18, La cursiva es del original). Esto significa que el sexo precede al/la sujeto/a; sin embargo esta determinación sexual es posible revertirse, o deconstruirse más bien, desde la elaboración cultural que, yendo más allá de lo señalado binariamente por la autora, implica la diversidad de género; no solo la generarización binaria. La diferencia entre los sexos, como dicen Alda Facio y Lorena Fries: 
[...] se concibió como la diferencia de las mujeres con respecto a los hombres cuando los primeros tomaron el poder y se erigieron en el modelo de lo humano. Desde entonces, la diferencia sexual ha significado desigualdad legal en perjuicio de las mujeres. Esta desigualdad podría haberse dado en contra del sexo masculino si el parámetro de lo humano hubiese sido a la inversa. Pero, está empíricamente probado que la jerarquización se hizo y se hace a favor de los varones. Es más en todas partes y en la mayoría abrumadora de las culturas conocidas, las mujeres somos consideradas de alguna manera o en algún grado, inferiores a los hombres. Cada cultura hace esta evaluación a su manera y en sus propios términos, a la vez que genera los mecanismos y las justificaciones necesarias para su mantenimiento y reproducción. (1)

Facio y Fries afirman que la diferencia entre hombres y mujeres tiene como base el ejercicio del poder; esto implica que la mujer ocupe una posición subordinada a la del varón y que el patriarcado perpetúe la desigualdad porque sencillamente le favorece. De igual manera, las autoras señalan que la inferioridad de la mujer es justificada por una "ideología 'sexual' [...] un sistema de creencias que no sólo explica las relaciones y diferencias entre hombres y mujeres, sino que toma a uno de los sexos como parámetro de lo humano" (3).

Esta ideología sexual patriarcal hegemónica, establece una línea de direccionalidad entre el sexo biológico-anatómico y el género; este último es conceptualizado como una entidad inmutable e inamovible en tanto solo es posible dimensionarlo a partir de la división hombre-mujer. A la biología-cuerpo que dice varón, le corresponderá una asignación cultural masculina y a la biología-cuerpo mujer, le corresponderá la asignación cultural femenina. Tenemos, entonces, culturalmente, un varón y una mujer signados por dos variables de género construidas históricamente por la cultura. Cuando introducimos la variable género o consideramos más bien al género en su dimensión exogenérica, nos referimos a la ruptura del binarismo de género. 
Respecto a esto último, Franke Alves de Atayde, señala acerca del pensamiento de Judith Butler que: "En El género en disputa, deconstruyó el concepto de género" (136) ya que "La división sexo/género funcionaba como una especie de pilar fundacional de la política feminista, en la medida en que ésta partía de la idea de que el sexo es natural y el género es socialmente construido" (136). La finalidad del feminismo de vincular sexo, en tanto categoría normativa, con esencialismo y género con cultura, permitiría romper con el determinismo biológico impuesto a los cuerpos lo cual tenía como continuidad la concepción de una construcción de género cultural binaria. El encapsulamiento de la mujer, ahora, en un binarismo cultural, sería, en último término, otra forma más de esencialización de la mujer, negando con ello la multiplicidad que encarna la sujeta en relación a las dimensiones de clase, etnia, edad (137). Para Butler el sexo también es una construcción cultural, así: "Tal vez el sexo siempre haya sido el género" (Franke Alves de Atayde 137). Siguiendo a Alvez de Atayde, "Para Butler el sexo es una categoría 'generizada'. Una categoría construida discursivamente a través del género" (138) ya que el lenguaje mismo de quien observa el cuerpo sexuado "están embebido de un lenguaje cultural" (ibíd.) y un punto de vista cultural, agregaría. Butler insiste en la imposibilidad de una subjetividad estable, de igual manera afirma que el sujeto es efecto del poder (Butler, Mecanismos 17) el cual puede desestabilizarse en el lenguaje (Franke Alves de Atayde 141). Me parece relevante incluir la posición de Butler, en tanto deconstruye todo binarismo y promueve la diferencialidad de la mujer y su carácter no unitario ni universalista lo cual no impide articulaciones políticas coyunturales con sujetes que experimentan marginación por raza, clase, género en su dimensión no binaria.

Richard, por el contrario, avala la unificación de mujeres y hombres, además, acepta el binarismo de sexo y género. Así dice:

La "literatura de mujeres" designa un conjunto de obras literarias cuya firma tiene valencia sexuada, sin que estas obras internalicen necesariamente la pregunta de cuáles son las construcciones de lenguaje 
que textualizan la diferencia genérico-sexual. La categoría de "literatura de mujeres" se moviliza para delimitar un corpus en base al recorte del género sexual, y para aislar ese corpus en búsqueda de un sistema relativamente autónomo de referencias-valores que le confiera unidad a la suma empírica de obras que agrupa. Es decir que "la literatura de mujeres" arma el corpus sociocultural que contiene y sostiene la pregunta de si existen caracterizaciones de género que puedan tipificar una cierta "escritura femenina. (32)

Richard afirma la existencia de una literatura de mujeres a partir de su autoría sexuada. Ello significa que está signada por la condición sexo-biológica de quién escribe. Estas escrituras, no necesariamente, han puesto en cuestión la diferencia sexo-género al interior de su escritura. Sin embargo, agrega, la literatura de mujeres se movilizaría en búsqueda de la ideología femenina que sostendría la construcción de la sujeta. La denominada literatura de mujeres, que seguiría la ruta señalada por Richard, correría el peligro de caracterizar la escritura femenina, derivando con ello en un esencialismo. Esto significa, identificar rasgos, elementos formas, típicamente femeninos, no rastreables en la escritura de varones. Consciente de ello, Richard advierte que el tipo de crítica se vería limitada a una

[...] concepción naturalista del texto, pensado como vehículo expresivo de contenidos vivenciales, define un tratamiento realista y figurativo de la literatura que falla con obras donde la escritura protagoniza un trabajo de desestructuración/reestructuración de los códigos narrativos que violenta la estabilidad del universo referencial y que desfigura el supuesto de verosimilitud de los mecanismos de personificación e identificación femenino-literarias. (33)

El problema aquí está dado porque el rótulo literatura de mujeres no puede solo resultar inválido en aquellas obras que se ubican fuera de los límites de la 
representación realista/figurativa, sino que al interior mismo de esa representación también es inútil. Por ejemplo, como ha quedado patente en la insistencia en el registro realista de las narrativas del nuevo milenio, no todo el realismo es naturalista y, además y esto es lo más importante, la sujeción a la convención realista/figurativa no implica necesariamente la ausencia de un sentido crítico y la presencia de elementos deconstructivos no implica, a su vez, la eliminación de la lógica naturalista, la cual corresponde con una visión positivista de la realidad, fuertemente clasista, ya que suele fijarse en los sectores económicamente frágiles, basado en el determinismo. Es decir, los ejes planteados para la caracterización no son excluyentes ni unidireccionales, sino que se encuentran imbricados produciendo entrecruces, como sucede en narrativas que solo en apariencia son deconstructivas, pero que están organizadas bajo una lógica conservadora. En lo que sí estoy de acuerdo con Richard es en distinguir que hay escrituras literarias ajustadas a lo representacional versus las orientadas a deconstruir lo representacional. A estas últimas las denominaré experimentales. Sin embargo, insisto, en ambos tipos de escritura es posible distinguir una perspectiva esencialista respecto a la mujer, ya que la ideología autoral puede ceñirse a los dictados patriarcales en ambos casos. No tenemos certeza, en el acto de lectura, de encontrarnos ante una voz autoral femenina, ligada a la lógica patriarcal, despatriarcalizada o en proceso de despatriarcalización. Es más, gran parte de las escrituras de mujeres, más que elaborar la emancipación, se centran en el proceso emancipatorio, que es abierto y constante.

A continuación, Richard agrega:

Por otra parte, esa crítica hace de lo "femenino" el referente pleno de una identidad-esencia (reuniversalizable como tal en su genericidad absoluta: "Es 'la mujer' la que habla, la de todos los tiempos, la de siempre, la sometida, la torturada, la que sufre el desamor y el olvido del hombre." ibid), sin tomar en consideración el modo en que identidad y representación se hacen y se deshacen en el transcurso del texto bajo la 
presión del dispositivo de remodelación lingüístico-simbólica de la escritura. (33)

Entonces, aquella crítica literaria que va tras la caracterización de género de la literatura de mujeres en virtud de tipificar una "escritura femenina", de acuerdo a Richard, esencializa y universaliza lo femenino sin considerar, sigo a la autora, que la representación se arma y desarma al interior del texto literario. Estamos de acuerdo en que las representaciones de subjetividad pueden ser deconstruidas en el devenir del texto; sin embargo, la autora no señala que también pueden permanecer fijas. Esto implicará, agrego, que en un texto se represente a una mujer a partir de un punto de vista binario, homogéneo y, por lo general, atado al paradigma de representación patriarcal o disidente a tales presupuestos. El tipo de crítica que se conforma con identificar aquello que caracteriza a sus personajes femeninos, insisto, a partir de las asignaciones de género derivadas del binarismo, tiene como resultado el esencialismo.

Con posterioridad, Richard afirmará que muchas escritoras asumen que "sólo hay buena o mala literatura" (34), y que el lenguaje no tiene sexo para evitar ser rebajadas al rango de lo particular (lo femenino) y perder espacio en el rango de lo general (lo masculino-universal)" (34). Si bien es cierto que Richard no comparte tales afirmaciones, también lo es que se niega a aceptar que exista un poder simbólico operando en el texto, en función de imponer una "clave monosexuada" (35). En esto último, vuelvo a disentir con Richard. El patriarcado es una lógica que ha operado y opera sobre la literatura imponiendo la representación unívoca de la mujer; es más, determinando temas, aproximaciones al tema y forma textual a las escrituras de mujeres. Toda escritura de mujer que se desvíe de tal encuadre, será excluida por la crítica o considerada de mala factura. Eso lo sabemos y vemos de manera recurrente. Richard cita a Josefina Ludmer, como ejemplo de visión compartida, quien señala "que la escritura femenina no existe porque toda escritura es asexual, bisexual, omnisexual" (35). Ludmer niega la existencia de la escritura femenina optando por una generalización, donde la escritura contiene todas las 
inflexiones sexuales. La autora, además, se refiere al igual que Richard, al concepto "sexo". Desde mi visión, si la escritura fuera asexuada estaríamos aceptando una neutralidad; sin embargo, el desacierto es mayor ya que la condición sexual se refiere, como se ha dicho, a un formalismo biológico que perfectamente puede estar disociado de la subjetividad del sujete. Por lo mismo, lo que es necesario afirmar es la inoperancia del término sexo y la necesidad de utilizar el concepto de género.

La distinción entre qué se entiende por sexo y género es fundamental para aproximarnos al texto de Richard. Sexo se refiere a las características biológicas que definen al macho y la hembra durante la gestación o nacimiento. Es decir, que a determinada configuración anatómico-biológica-genital-sexual visible le será asignada uno de estas dos categorías de género, por supuesto, excluyentes: mujerhombre. Esto implicará una educación e inserción social donde él/la sujeto/a deben adaptarse a lo que la naturaleza les ha impuesto (cf. Lentes de género 21-26). Es necesario agregar que aun cuando se considerara que la diferencia sexual es biológica o anatómica, sería un error, debido a que esta configuración requiere de una interpretación cultural. Insistiendo en la construcción social del género, Francesca Gargallo nos dice:

Los géneros son construcciones sociales que, con base en los genitales de un cuerpo humano, transforman ese cuerpo en sexuado (eso es, destinado a la reproducción) y asignado a un sistema jerárquico que considera inferior lo femenino y descarta cualquier opción que no sea el reconocimiento de ser hombre o mujer (asignación forzada de un género a toda intersexualidad y desnaturalización de la misma). La superioridad del hombre es por tanto una compleja construcción cultural que se absolutiza en todos los países dominados por la cultura que la produce. A la vez, esta construcción tiene características parecidas al racismo de la conquista y a la esclavización de los vencidos, de tal forma que sistema de géneros y guerra, sistema de géneros y colonialismo se acompañan y refuerzan uno 
a otro, porque tienen un mecanismo de jerarquización común en su base. (24)

El carácter sexuado del cuerpo humano se debe a sus genitales, ligado a la reproducción y sostenido en una jerarquía binaria. El lugar privilegiado que ocupa el hombre es universal, dice Gargallo, asimilando esta construcción como una guerra donde el sistema de género opera del mismo modo que el racismo o la colonización, en el cual el dominador es el poder y el subalterno el dominado. En esta misma línea se ubica María Luisa Femenías cuando se refiere a la noción de género asimilada a la construcción social, por tanto se trataría de "un conjunto de propiedades y funciones que una sociedad le atribuye a sus integrantes en virtud de su sexo, entendido como dato biológico" (8). Para luego agregar que se piensa género, "como fuertemente vinculado al sexo (o "causado" por este), biológicamente dado, inmodificable de por vida y estático" (8). Para Femenías, con quien coincido, se cambia el término esencia por naturaleza. Esto significa que si bien el género se asocia a la creación cultural, por tanto adquirido, no por ello se desprende de la distinción esencialista masculino-femenino. Lo más grave es que al ligar sexo con género se normaliza tal binarismo, eliminando la deriva del concepto mismo de género.

De acuerdo a Richard, citando a Kristeva, hay un más allá de los condicionamientos biológico-sexuales y psico-sociales que definen "al sujeto autor e influencian ciertas modalidades de comportamiento cultural y público" (35). Con esto, Richard se apega a una postura psicoanalítica de base esencialista donde:

[...] la escritura pone en movimiento el cruce interdialéctico de varias fuerzas de subjetivación. Al menos dos de ellas se responden una a otra: la semiótico-pulsional (femenina) que siempre desborda la finitud de la palabra con su energía transverbal, y la racionalizante-conceptualizante (masculina) que simboliza la institución del signo y preserva el límite sociocomunicativo. Ambas fuerzas coactúan en cada proceso de 
subjetivación creativa: es el predominio de una fuerza sobre la otra la que polariza la escritura sea en términos masculinos (cuando se impone la norma estabilizante) sea en términos femeninos (cuando prevalece el vértigo desestructurador). Ciertas experiencias límite de la escritura que se aventuran en el borde más explosivo de los códigos, como sucede con las vanguardias y neovanguardias literarias, desatan dentro del lenguaje la pulsión heterogénea de lo semiótico-femenino que revienta el signo y transgrede la clausura paterna de las significaciones monológicas, abriendo la palabra a una multiplicidad de flujos contradictorios que ritman el quiebre sintáctico. (35)

La cita anterior afirma la existencia de procesos de subjetivación ligados al binarismo masculino-femenino donde identifica para lo femenino una fuerza energética que va más allá de la palabra, "transverbal", desestructurante, y atribuye a lo masculino una fuerza racionalizante-conceptualizante, apegada a significaciones monologizantes. Si bien ambas fuerzas coactúan en el proceso comunicativo y creativo, no deja de ser llamativo que lo femenino quede excluido, por sí mismo, de lo racional. Se trataría así de una operación de retroalimentación de ambas fuerzas, donde una logra sobreponerse a la otra, dando como resultado, según sea la fuerza energética que predomine, una escritura masculina o femenina. La neovanguardia o vanguardia a secas, ejemplos que pone la autora, se harían parte, entonces, de una lógica femenina. Esta conclusión implicaría, siguiendo a Richard, que más allá del sexo, aquello que determinaría una escritura como femenina o masculina sería la activación de un proceso de subjetivación que carga una pulsión energética femenina o masculina. Las vanguardias y neovanguardias serían un ejemplo de escrituras femeninas, ignorando - con ello- el concepto de cultura y de género. Con posterioridad la autora señala:

Más que de una escritura femenina, convendría entonces hablar cualquiera sea el género sexual del sujeto biográfico que firma el texto- de 
una feminización de la escritura: feminización que se produce a (sic) cada vez que una poética o que una erótica del signo rebalsan el marco de retención/contención de la significación masculina con sus excedentes rebeldes (cuerpo, libido, goce, heterogeneidad, multiplicidad, etc.) para desregular la tesis del discurso mayoritario. Cualquier literatura que se practique como disidencia de identidad respecto al formato reglamentario de la cultura masculino-paterna; cualquier escritura que se haga cómplice de la ritmicidad transgresora de lo femenino-pulsional, desplegaría el coeficiente minoritario y subversivo (contradominante) de lo "femenino". Cualquier escritura en posición de descontrolar la pauta de la discursividad masculina/ hegemónica compartiría el "devenir-minoritario" (DeleuzeGuattari) de un femenino que opera como paradigma de desterritorialización de los regímenes de poder y captura de la identidad normada y centrada por la cultura oficial. (35-36. Las cursivas son del original)

Richard se refiere a un más allá del género biográfico al que pertenece el autor o autora, que no es precisamente el género no binario. De acuerdo a esto, cada vez que una poética o erótica del signo excede sus marcos de significación masculina, es porque ocurre una desregulación del discurso masculino; lo cual se manifiesta con la presencia, en lo masculino, de un excedente femenino/rebelde (“cuerpo, libido, goce, heterogeneidad, multiplicidad, etc.”). Esta perspectiva, demuestra la imposibilidad de salir del binarismo masculino/femenino; la autora, ante tal situación, realiza un operación de trasvasije, donde aquellas características que definen lo femenino pasan a ocupar el lugar de lo masculino, dando lugar a la feminización de la escritura. La antihegemonía literaria, por tanto, estaría signada por la presencia de características propias de lo femenino, repito, el predomino del “cuerpo, libido, goce, heterogeneidad, multiplicidad, etc.". Para la autora esta apertura tiene: 
[...] la ventaja de romper el determinismo biológico de que funciones anatómicas (ser mujer/ ser hombre) y roles simbólicos (lo femenino/lo masculino) se correspondan naturalistamente, basados en el mito de la Identidad-Una del cuerpo de origen. Desligar ambas construcciones del realismo naturalista del cuerpo originario, permite darles movilidad de signos a los masculino y a lo femenino; signos que se desplazan y se transforman según las dinámicas de subjetividad que cada proceso simbólico-sexual va formulando en respuesta a los llamados del modelo social de identidad dominante. Tal como "ser mujer" no garantiza por naturaleza el ejercicio crítico de una femineidad necesariamente cuestionadora de la masculinidad hegemónica (no de sus parámetros culturales dominantes), "ser hombre" no condena al sujeto/autor a ser fatalmente partidario de las codificaciones de poder de la cultura oficial ni a reproducir automáticamente sus mecanismos, por mucho que la organización patriarcal busque convencerlo de sus beneficios. (36-37)

El esencialismo o determinismo biológico se rompería a través de la movilidad que se impone al signo masculino, ahora dinamizado, en transformación, confrontando a las imposiciones del modelo hegemónico. Hacia el final del párrafo citado, la autora, y con esto concuerdo, afirma que ser mujer no es garantía de una "femineidad" que cuestione los patrones masculinos y que ser hombre, además, no condena a reproducir las codificaciones patriarcales. Este salvavidas que Richard lanza a la masculinidad, la lleva a ejemplificar en las escrituras de Juan Luis Martínez, Raúl Zurita, Gonzalo Muñoz y Diego Maquieira, una tradición que arruina el yo de la tradición épica y lírica (37), orientada a "lanzar sus escombros contra la imagen trascendental del hablante metafísico" (37), inscribiendo, además, en sus producciones, las "parodias transexuales (sic) de roles masculinos y femeninos que se alternaban y rotaban en la voz montajista del poeta que era también voz de lumpen, de prostituta, de travesti, de guerrillero y de santa" (37). La caracterización que la autora realiza de la escritura de los poetas mencionados 
es parte de una poética que no "toca" al patriarcado. En última instancia, Richard ve los recursos estilísticos como ideología en una textualidad genéricamente híbrida. Cada uno de ellos revelaría en sus obras una fuerte presencia de la metafísica, como casi toda la poesía chilena, y del recurso alegórico para dar cuenta del estado de caos generalizado durante la dictadura, periodo en que comienzan a publicar sus obras. Los signos de ruptura van más por deconstruir el género poético y levantar una nueva épica o contraépica, donde la voz omniabarcadora del poeta fuera capaz de concitarlo todo. Así, estamos en presencia de una ruptura que abarca dos ámbitos específicos: uno más restringido, la convención genérico-literaria, es decir, un ámbito político-estético y otro, el orden más amplio, la dictadura, disidencia clave en los mencionados autores. En ningún caso se aprecia la disidencia al orden patriarcal como eje político de estas propuestas. Es más, insisto, tanto Martínez como Zurita asumen en su poética una voz mesiánica, donde privilegian un hablante omnisciente y la presencia de lo femenino no es más que un símbolo, subalterno a la voz lírica.

Richard para confirmar su punto de vista, cita a la crítica Soledad Bianchi quien así dice: "se hace necesario quebrar el "ghetto" del sexo y se trataría de situarlos (los textos de mujeres) junto a los otros producidos por los contemporáneos hombres y mujeres considerando semejanzas y diferencias, reconociendo logros y aportes, pero también limitaciones" (37). A lo anterior, Richard agrega:

Al no reconocer esas limitaciones, la crítica feminista corre el riesgo de sobreproteger las producción de mujeres y de prolongar así su invalidez, marginándola del campo de batalla de la cultura donde se pelean las estrategias de signos [...] podemos, en nombre de la Diferencia, censurar una (otra) diferencia que es vital para la crítica feminista: la que separa aquellas producciones femeninas aún subordinadas a las formas de la ideología cultural dominante (por mucho que una militancia feminista programe y justifique sus contenidos temáticos) de aquellas producciones 
rebeldes a los montajes de la cultura oficial y gestadoras (sic) de técnicas capaces der desatar conflictos de lecturas en el interior de sus formalizaciones socioliterarias. (37-38)

Tanto Bianchi como Richard señalan la necesidad de evitar el gueto, la comunidad de mujeres que, en términos críticos, "sobreprotegería" las producciones literarias de las autoras o "censurar" producciones de autoría varón no cómplices con las formulaciones programadas desde la oficialidad masculina. Ambas teóricas no consideran que tanto las historias de la literatura como el canon y la crítica han sido y son patrimonio de las masculinidades; además, que hay una diferencia gravitante en lo que respecta a ocupar un lugar en el mundo como hombre o mujer y todas las amplias modulaciones de género (LGBT y más). No se trata de censurar, desde mi perspectiva, sino asumir que la diferencia de género produce textualidades diversas y que aquellas escrituras de varón que desafíen la autoridad patriarcal estético-ideológica no deben situarse al interior del feminismo, sino en el ámbito de la despatriarcalización (Cf. Galindo). Si hay un lugar común al cual oponerse, este es el patriarcado. Unificar luchas es necesario, sin olvidar que en términos de escrituras no es posible homogenizar ya que la anulación del género implica destruir la diferencia de subjetividades. Es más, la práctica de la cancelación de autores/autoras, implica su olvido, por tanto debería considerarse que aquellas producciones misóginas, xenófobas, homofóbicas y pro abuso infantil, deben ser objeto de crítica ya que representan la "escena del crimen", el lugar donde habita el relato del odio. Por tanto, más que cancelación, propongo una crítica implacable.

Concuerdo con Richard en que hay producciones femeninas aún subordinadas a las formas de la ideología cultural dominante, tanto en el tratamiento contenidista como formal. Considero que la literatura de mujeres, categoría en la cual se debe explicitar y remarcar la inclusión de las mujeres trans, debe intervenir el género literario, el montaje de la escritura, asumiendo una política de la letra misma, que permita visibilizar la crisis de subjetividad y su contraposición con las 
masculinidades patriarcales. Es decir, yendo más allá de las temáticas, estilos y representaciones que históricamente han sido asociados a la mujer escritora; en otras palabras, decolonizando todas aquellas escrituras que el patriarcado ha construido como novela, cuento, poema, ensayo, crónica. En ese sentido Richard señala que:

[...] las mujeres no pueden darse el lujo de no sacar provecho de lo que se libra (de lo que se gana o se pierde) en esas batallas, [disputas de hegemonías de códigos materiales e interpretativos], ya que todas ellas contienen entrelíneas rebeldes con los cuales complicitarse (sic) en refuerzo a la propia empresa femenina de desmantelamiento del edificio simbólico-cultural de la cultura patriarcal. (39)

Esta perspectiva indica que las mujeres deben asociarse a los hombres, un enemigo no total, sino a aquellos que realicen un trabajo antipatriarcal. Estos juicios en torno a colectividades masculino-femenino, resultan desde mi visión, reproductores de la política chilena de posdictadura. La Concertación de partidos por la democracia, hizo suyo el slogan de construir una nueva patria a partir de la unidad, olvidando diferencias, en pos de un objetivo común. Evitar el llamado reducto o gueto de mujeres será el objetivo de la propuesta de Richard que llama a unificar fuerzas con hombres deconstruidos. Esta visión, implicaría, por ejemplo, que un escritor vanguardista, si nos ponemos en el contexto en que fue escrito el texto de Richard, que esté contra el canon y la estética dominante pasaría a ser un aliado de las feministas. Esto implica una separación entre la literatura y la vida del autor o la validación del simulacro de deconstrucción masculina, ya que solo se requiere de un pasaporte estético para ingresar al territorio feminista. La autora, hacia el final de su texto, señala que:

[...] si bien el gestualismo contestatario del disolver la autoridad paterna no es exclusivo ni privativo de las prácticas de mujeres, no es menos cierto 
que las mujeres se enfrentan a la alternativa norma/infracción bajo circunstancias especiales que las predisponen especialmente a los excesos. Algunas buscan conjurar el peligro de la crisis desintegradora de las estructuras sociales, exagerando -defensivamente- su respuesta de conformismo a las ideologías de orden religioso, familiar, nacional. Otras desacatan el mandato simbólico-masculino y lanzan su ofensiva contra la defensa patriarcal del sistema de identidad, desatando en su interior la revuelta espasmódica de la desindentidad. La escritura es quizás el lugar donde ese espasmo de revuelta opera más intensivamente: sobre todo cuando la palabra, subjetividad y representación, desencajan sus registros ideológicos y culturales hasta que revierte la unidad lingüística que amarra el sentido a la economía discursiva de la frase. Y hasta que explote con ella los códigos de la identidad represivamente edípica-familiarista, dando lugar al renacer transsexual (sic) de un sujeto ya "desmaterna y despaterna". (42. Las cursivas son del original)

Asociar lo contestatario con una mera gestualidad me parece un tanto displicente. La autora, en cualquier caso, afirma que no es patrimonio de la mujer el ejercicio de la práctica rebelde. Una vez más, confirma su voluntad integradora de lo masculino. Si bien estoy plenamente de acuerdo en que el desacato al patriarcado no es privativo de mujeres, disiento de asignar a la mujer, de modo esencialista, el exceso ya sea para "defender" el orden patriarcal o desmontar el mismo. Este exceso, podría, eventualmente ser asociado a la necesidad de la subalterna de adoptar una estética del desborde como táctica de confrontación ideológica. Sin embargo, las escrituras literarias de mujeres dicen lo contrario. Hay un consentimiento a los modos de escritura impuestos desde la heteronorma, es más, las escrituras revelan la puesta en práctica de una estética más austera que desbordante. La afirmación de Richard no hace más que confirmar una nueva oposición entre mujeres y hombres, aquella que confronta contención con hipertrofia, lo cual nos lleva a las delimitaciones patriarcales entre el signo de lo 
normativo-legitimado versus el no-legitimado. La validación de las escrituras de varón feminizado o deconstruido, reclama "para los hombres el espacio privilegiado del desplazamiento, normalmente reservado en la deconstrucción para la Mujer”2 (Fuss 135). Las escrituras de mujer obedecen, como en toda autoría, a la ocupación de un lugar asignado o no asignado. Con esto quiero decir que la escritura puede agenciarse al modelo patriarcal o desobedecerlo u operar al unísono ya que me refiero a límites inestables en las diversas posiciones de sujeta.

Recogiendo lo señalado a través de este texto: todo libro posee un nombre autoral inscrito en la portada. Esta firma implica siempre una marca binaria: masculino o femenino. Leemos, de tal modo, a partir de un condicionamiento cultural de base esencialista que nos impone una matriz binaria, patriarcal, encargada de asignar temáticas y modos de escritura a la producción literaria de mujeres. Esta asignación implica la construcción de un femenino creado por la ideología patriarcal; es decir: subordinado, pasivo, heterosexual.

Es necesario agregar que la naturaleza femenina es una elaboración del patriarcado y que la distinción de sexo biológico-anatómico, sustenta el binarismo sin considerar el concepto de género, el cual nos remite a una construcción cultural no binaria. Un cuerpo biológicamente varón o mujer, no posee un en sí, una esencia ni una ideología necesariamente adscrita ni al sexo ni al género. Debemos concebir al género, por ende, como una construcción representada (De Lauretis 9). Como tal, el género es:

[...] la representación de una relación, ya sea que pertenezca a una clase, a un grupo o a una categoría. El género es la representación de una relación, o, si puedo, por un momento, entrometerme con mi segunda proposición, el género construye una relación entre una entidad y otras entidades que están constituidas previamente como una clase, y esa relación es de pertenencia; de este modo, el género asigna a una entidad,

\footnotetext{
${ }^{2}$ Mayúscula del original.
} 
digamos a un individuo, una posición dentro de una clase y, por lo tanto, también una posición vis-a-vis con otras clases preconstituidas. (10)

El género representa, así, una relación, un vínculo o posición con una clase preconstituida que fomenta la asimetría entre masculino y femenino. Por tanto, será necesario considerar, en primer lugar que cuando hablamos del sujeto del feminismo no nos referimos a la $\mathrm{Mujer}^{3}$ (7) universal (16) ya que esta no es una esencia sino una construcción, en constante elaboración. La escritura de mujeres, por tanto, se ve tironeada por el sexo y el género, ambos operando como condicionamientos orientados a la asignación de un lugar y un discurso. Esto nos podría llevar a pensar en la necesidad de deconstruir tanto el sexo como el género sin que ello signifique una nueva reconstrucción. Concuerdo con De Lauretis cuando señala que el género se encuentra tensionado por la representación y aquello que la representación omite (34). Ahora: ¿qué es lo omitido del género? Desde mi perspectiva, lo omitido se refiere a todo aquello que expulsa, que rechaza la noción de género binaria y la teoricidad sesgada que niega no solo la experiencia situada de las mujeres sino también su condición de clase, condicionamiento que opera, sin querer entrar en el fondo de la cuestión, junto al género.

Cuando Richard se refiere a su visión de la escritura antihegemónica, antipatriarcal como no privativa de la mujer y advierte el beneficio que se obtendría de unificar fuerzas entre varones y mujeres, no rompe con el esencialismo de la mujer, sino que al contrario, lo afirma. Su propuesta unifica, a fin de cuentas, dos esencialismos, el masculino y el femenino, en pos de una estética que, desde mi perspectiva, anula la diferencialidad de género. Entendiendo esta diferencialidad de género como un más allá de la imposición del fundamento biológico que establece la diferencia a partir de "la caracterización sexual [que] valida la desigualdad entre unos y otras" (Hernández 118).

\footnotetext{
${ }^{3}$ Con mayúscula señala De Lauretis.
} 
Claramente en posible afirmar la existencia de literaturas experimentales, que vayan en contra de la hegemonía literaria. Asimismo, es posible hablar de escrituras marginales, devenidas de lo minoritario de acuerdo a etnia, clase, género, cuyo autor o autora se manifieste en desacuerdo con la hegemonía masculinizante. Sin embargo no me parece posible que este conjunto de escrituras de la minoridad, dando lo mismo el género, sea considerable como escrituras feminizadas. Esta posición no hace más que reproducir lo que ha sido el influjo histórico de una normativa masculinizante. Si bien es imposible remitirnos a la mujer como un universal, es necesario asumir que no es lo mismo ser educada como mujer, varón o trans. Culturalmente hemos sido creadas como entidades funcionales al patriarcado lo cual marca una diferencialidad de género abismante respecto al modo de educación que recibe un varón. Por tanto, cuando se trata de escrituras, la mujer que se construye y deconstruye al interior del texto, está siempre en disputa o sumisión con la asignación de atributos genéricos devenidos de la cultura patriarcal. Las escrituras de mujeres, es necesario agregar, van ligadas a un posicionamiento político (García 11), en el entendido que necesitamos articular un lugar de escritura/habla que desautorice o ponga en crisis el determinismo patriarcal. Cuando leemos a escritoras que abordan topoi esencialistas como la gestación, la relación amorosa o la relación maternal, podemos apreciar la mera reproducción de esencialismos de género, regulaciones que la cultura ha impuesto a las escrituras de mujeres (Vivero 72-73), o su crítica; por lo tanto, en caso alguno la presencia de esos topoi evidencian rasgos específicos de la escritura de mujeres. Estas características representan el estrato patriarcal, aquel que asigna tales temáticas a la mujer; sin embargo, insisto, estas características o vectores pueden modularse al modo celebratorio - que impone el contrato patriarcal—o ser reelaboradas a partir de una movilización de una subjetividad de mujer en proceso de un posicionamiento político. 


\section{Bibliografía}

Alves de Atayde, Franke. "Performatividad y política en Judith Butler". Eikasia. Revista de Filosofía, año V, 39 (julio 2011): 133-151.

Butler, Judith. Lenguaje, poder, identidad. Madrid: Síntesis, 1997. . Mecanismos psíquicos de poder. Teorías sobre la sujeción. Madrid: Cátedra, 2001.

Castillo, Mayari. "Construyendo categorías para pensar la agencia política en sociedades desiguales. Una reflexión sobre Arendt y Butler". Revista Internacional de Pensamiento Político, I Época, Vol.7, 2012 (275-289).

De Lauretis, Teresa. "La tecnología del género". Debate feminista N², 1990: 634.

Fuss, Diana. "Leer como una feminista" en Carbonell, Neus y Meri Torras (comp. y edit.). Feminismos literarios. Madrid: Arco/Libros, 1999: 127146.

Facio, Alda y Lorena Fries. "Feminismo, género y patriarcado". Academia, Revista sobre enseñanza del derecho de Buenos Aires, Año 3, $\mathrm{N}^{\circ} 6$, Primavera 2005: 259-294.

Fausto-Sterling, Anne. Cuerpos sexuados. Barcelona: Melusina, 2000.

Femenías, María Luisa. Itinerarios de teoría feminista y de género. Algunas cuestiones histórico-conceptuales. Quilmes: Universidad Nacional de Quilmes, 2019.

Galindo, María. No se puede descolonizar sin despatriarcalizar. Bolivia: Mujeres Creando, 2013.

García, Nagore. "Palabra y cuerpo: el género en la escritura o la escritura del género". Actas del I Coloquio Hispano-Ruso sobre Mujer y Literatura. San Petersburgo: Universidad Pedagógica Estatal Herzen, 2015: 9-18.

Gargallo, Francesca. "Feminismo Latinoamericano", Revista venezolana de estudios de la mujer, 12 (28), 2007: 17-34.

Hernández, Josefina. "El género y la escritura femenina". Revista mexicana de ciencias políticas y sociales, vol. 48, $\mathrm{n}^{\circ}$ 197, México, mayo/agosto 2006: 117-135.

Lugones, María. "Colonialidad y género". Tabula Rasa, Bogotá-Colombia, N 9, julio-diciembre 2008: 73- 101.

Richard, Nelly. “¿Tiene sexo la escritura?”. Masculino/Femenino: prácticas de la diferencia y cultura democrática. Santiago de Chile: Francisco Zegers Editor, 1993.

VV.AA. "Lentes de género. Lecturas para desarmar el patriarcado". Serie derechos humanos. Género y derechos de las mujeres $\mathrm{N}^{\circ} 1$, Caracas, Defensoría del Pueblo, 2010. 
Vivero, Cándida. "El género en la teoría literaria". Géneros. Revista de investigación y divulgación sobre los estudios de género, Número 4/ Época 2, Año 15/ Septiembre 2008-Febrero 2009: 67-74. 